\title{
Integrative pedagogical technique of physical education of female students with overweight
}

\author{
Kolokoltsev M.M. ${ }^{1 \mathrm{ABCDE}}$, Ambartsumyan R.A. ${ }^{1 \mathrm{BCD}}$, Tretyakova N.V. ${ }^{2 \mathrm{CDE}}$, Jagiello W. ${ }^{3 \mathrm{ABCD}}$, Yermakova T.S. ${ }^{4 \mathrm{ABCD}}$ \\ ${ }^{1}$ Irkutsk National Research Technical University, Russia \\ ${ }^{2}$ Russian State Professional Pedagogical University, Russia \\ ${ }^{3}$ Gdansk University of Physical Education and Sport, Poland \\ ${ }^{4}$ Kharkiv State Academy of Design and Arts, Ukraine
}

Authors' Contribution: A - Study design; B - Data collection; C - Statistical analysis; D - Manuscript Preparation; E - Funds Collection.

\begin{abstract}
Purpose: $\quad$ design and testing of the integrative pedagogical technique of physical education, aimed at the female students' overweight correcting.

Material: $\quad$ The anthropometric examination of 1 st-year female students $(n=397)$ was carried out. The female students were referred to the special medical group according to the health condition. Overweight female students $(n=86)$ were selected for the pedagogical experiment. The female students were divided into 2 groups: experimental $(n=42)$ and control $(n=44)$. Anthropometric and physiometric parameters were determined. The body mass index, Robinson index, and power index were calculated. The motor qualities of female students were evaluated by tests. The female students attended the academic classes "Elective courses in physical education and sports" 2 times a week. The pedagogical technique "inverted class" was applied: the previous self-study of the material on electronic gadgets or on the Internet; subsequent detailed analysis of the gained knowledge in the classroom.

Results: $\quad$ By the end of the pedagogical experiment, the female students of the experimental group demonstrated the decrease in body mass in $12.6 \%$, functional characteristics of the cardiovascular system improved, and power and motor abilities' parameters increased $(p<0.05)$. The body mass index corresponded to normal values in 20 female students (47.6\%) at the end of the experiment. The body mass index decreased by $13.8 \%$ in 12 female students (28.6\%). The body mass index did not change in 10 female students (23.8\%). The female students of the control group demonstrated lower results than female students of the experimental group.

Conclusions: The integral pedagogical technique is based on a combination of the "inverted class" method and digital learning. Pedagogical techniques considered to be more effective for female students' body mass correcting than the traditional one.

Keywords: female students, body mass correction, integral pedagogical technique, physical education.
\end{abstract}

\section{Introduction ${ }^{1}$}

The World Health Organization (WHO) experts note that in many countries of the world there is a decrease in the number of people with normal body mass [1]. The particular importance in scientific research is given to the study of the body mass deviations from the norm among students.

The important task of the higher education system is to create conditions for students' health maintaining and promotion. The special role is given to physical education, which is a leading factor in health promotion [2] and students' mental performance optimizing.

Physical educations classes are conducted according to the standard methodology (2-3 times a week) and do not always lead to a positive result on the students' body mass correction. It is not possible nowadays to increase the number of academic classes in physical education. Therefore, some authors propose the additional use of corrective classes programs at the out-of-lesson time [3]. However, elective physical education classes are not always highly effective [4]. Therefore, an important direction of the health-saving process is the search

\footnotetext{
(c) Kolokoltsev M.M., Ambartsumyan R.A., Tretyakova N.V., Jagiello W. Yermakova T.S., 2019

doi:10.15561/20755279.2019.0605
}

for new pedagogical techniques (form organization of academic classes) to increase motor activity and students' body mass correction.

The important issue in the physical education of students is the use of information and communication technologies. Such a direction is a good promotion of fitness systems and physical activities. This is especially important for the younger generation and students.

One of the important parameters of the physical development of an individual is a person's body mass. The body mass is considered as an integral level characteristic and condition of metabolic, hormonal, growth, energy processes in the body $[5,6]$. The body mass deviation from the norm should be considered as a predictor of human health deterioration.

Overweight and obesity can significantly affect the somatic, physical, reproductive and mental health of the person. This contributes to type 2 diabetes, atherosclerosis, hypertension [7], which leads to coronary and cerebral blood supply disturbance [8]. The hormonal status disorders [9], impaired productivity [10] and a decrease in life expectancy [11] are fixed in obese people.

The body mass deviation from normal indicates a serious violation of energy processes in the body [12, 13]. This parameter negatively affects the professional 
sphere of activity [14], complicates pregnancy and childbirth [15], and may affect the biological function of motherhood [16].

Recent studies show that body mass deviations from the norm are widespread among the world's population. In 2016 , more than $39 \%$ of the world's adult population has overweight, and 13\% were obese [1]. The Russian Federation is not an exception, where the annual increase in obesity is $0.4 \%$ [17] of the population. The number of students with body mass deviation at educational institutions of the Russian Federation reaches 30-40\% [18]. The following results were revealed In Russian universities: $10.7 \%$ of medical students in Kemerovo had overweight, and $4.8 \%$ are obese [19]; the overweight was revealed in $18.6 \%$ of students in Tomsk [11]; the overweight was revealed in $7.2 \%$ of students in Ufa [20]; $10 \%$ of female students in Yaroslavl had obesity [21]. The similar results were determined in Polish universities: during the last fifty years, the average percentage of fat in students from a technological university increased by $6.3 \%$, while this parameter in students from physical education university increased by $3.5 \%$ [22]. The average body mass index in the United States students was 27.29 $\pm 6.20 \mathrm{~kg} / \mathrm{m} 2$ in the overweight range [23]. Students in Ghana have $12.2 \%$ of overweight [24]. $12.1 \%$ of Ukrainian students had obesity [25].

The reasons for body mass deviation from the norm can be the follows: eating disorders and disruption of the hormonal condition of a person [11]; decrease of the physical activity [26]; mental trauma [27]; adverse environmental and anthropopressor factors. More obese people live in urban areas than in rural areas [2]. Insufficient physical activity is observed in almost $40 \%$ of the population of Russia: $37.0 \%$ of men, $42.0 \%$ of women [28].

In the WHO documents [29], the leading role in overweight prevention is given to increasing the level and quality of the motor activity. This is related to educational institutions and the nutritional correction of various population groups. The use of fitness technologies helps to normalize body mass $[30,31]$, especially in combination with nutrition correction [32]. Some researchers offer programs for extra health classes at an out-of-lesson time for students [18]. Regular sport exercises can solve many problems associated with overweight $[33,34]$. The urgent problem remains the search for new methods and improvement of existing methods and forms of fitness techniques aimed at body mass correction.

The use of information and communication platforms in physical education and sports is considered to be a promising direction $[35,36]$. The pedagogical technique "inverted class" provides for the previous self-study of the material on electronic gadgets or on the Internet; subsequent detailed analysis of the gained knowledge in the classroom [37]. However, this technique is not presented in the literature related to body mass correction.

The method of self-study using video cases, which represent the short and understandable programs is becoming popular [38]. The use of the integrative pedagogical technique (a combination of the "inverted class" teaching method and the digital learning method) for body mass correcting of female students of the special medical group is not presented in the literature.

Purpose of work: design and testing of the integrative pedagogical technique of physical education, aimed at students' overweight correction. The basis of this technique is a combination of the "inverted class" method and the digital method.

\section{Material and methods}

The participants. The study was conducted during the school year (35 weeks, September 2018-May 2019). It was performed using standard methods [39], anthropometric and physiometric monitoring of 1st-year female students $(\mathrm{n}=397)$ (Russia, Irkutsk National Research Technical University). The female students were referred to the 3rd functional group (special medical group) according to health reasons. 86 students with a high body mass index (BMI) were selected for the pedagogical experiment. Among them 73 female students (18.3\%) had overweight. 13 female students $(3.3 \%)$ had first-degree obesity. The female students divided into 2 groups: experimental (EG, $\mathrm{n}=42)$ and control $(\mathrm{CG}, \mathrm{n}=44)$.

To characterize the anthropometric and physiometric parameters of the female students the following parameters were determined:

- body length, cm;

- body mass, kg;

- chest circumference (CC), cm;

- Martine-Kushelevsky test (physical activity in the form of 20 squats in $30 \mathrm{sec})$ :

- $\quad$ heart rate before loading (HR), beat/10 s;

- heart rate after 20 squats in $30 \mathrm{~s}$ (HR), beat $/ 10 \mathrm{~s}$;

- recovery time of heart rate after 20 squats, min;

- $\quad$ systolic blood pressure (SBP) and diastolic blood pressure (DBP), $\mathrm{mm} \mathrm{Hg}$;

- Hand dynamometry, $\mathrm{kg}$ (Handgrip Strength Test, kg). It was expected the following:

- the Kettle's mass-height index (body mass index) [40];

- $\quad$ BMI = body mass / body length $\left.{ }^{2}, \mathrm{~kg} / \mathrm{m}^{2}\right)$;

- Robinson index [41] [IRob = (HR x SBP) / 100 c.u. $)$; - power index [SI = (muscle strength of the hand / body mass) x 100\%] [42].

BMI was evaluated according to the WHO classification (1999) [43]. The following parameters determined: body mass deficit (BMI $<18.5 \mathrm{~kg} / \mathrm{m}^{2}$ ); norm $\left(\mathrm{BMI}=18.5-24.99 \mathrm{~kg} / \mathrm{m}^{2}\right)$; overweight $(\mathrm{BMI}=25.0-29.9$ $\left.\mathrm{kg} / \mathrm{m}^{2}\right)$; various degrees obesity (BMI $\left.>30 \mathrm{~kg} / \mathrm{m}^{2}\right)$.

During the same periods of observation, students' motor qualities were evaluated. A set of tests was used [38, 39]:

1) $1000 \mathrm{~m}$ run, min, s;

2) $30 \mathrm{~m}$ run from a high start, s;

3) Bent Arm Hang Test (two hands), s;

4) Standing Forward Bend, cm;

5) Standing Long Jump Test (Broad Jump), cm;

6) Cadence Push-Up Test, the quantity of times; 
7) Eurofit Sit Up Test (for $30 \mathrm{~s}$ ), the quantity of times.

Organization of research. The pedagogical experiment performed from September 2018 to May 2019.

Students attended academic classes "Elective courses in physical education and sports" 2 times a week. The students had a doctor's permission to perform prolonged aerobic exercise.

To increase the weekly motor activity and motivation of the female students from the EG, the "Do it by yourself" video exercise complex was used. The video system sent to the personal email address of each female student. The video complex designed at the Department of Physical Culture of the Irkutsk National Research Technical University (Russia). The video complex aimed at reducing body mass. The video complex contains comments and recommendations on self-study of 10 body-oriented physical exercises of a power orientation. $30 \mathrm{~s}$ was given for performing each exercise. $30 \mathrm{~s}$ was given to take rest after the exercise. The duration of the full complex was 10 $\mathrm{min}$. The female students were recommended to perform 2 sets (only 20 minutes per day) 5 times a week.

At the end of the preparatory part of the academic class of the discipline "Elective courses in physical education and sports", students of the EG performed pre-learned exercises (1 set of "Do it by yourself" complex of 10$12 \mathrm{~min}$ ). The motor density of the lesson was increased by reducing the time for explanation and demonstration of exercises. We consider such a teaching method as an element of pedagogical technique "inverted class". In the main part of the class (40-45 min), power exercises with physical activity of aerobic nature of low and medium intensity were offered. The final part of the lesson (10$15 \mathrm{~min}$ ) includes relaxation exercises, movements' coordination, and flexibility, breathing recovery. The directed physical activity of the EG female students was 280 minutes per week (180 minutes of classes and 100 min of self-study). The weight in the form of $0.5 \mathrm{~kg}$ dumbbells and body mass was proposed to use. Additionally, the female students of the EG were recommended a list of Internet web sites devoted to eating behavior and motor condition.

The female students of the CG have engaged only in the standard curriculum of the discipline "Elective courses in physical education and sports": weekly physical activity is 180 minutes.

The carried out work does not infringe upon the rights and does not endanger the well-being of students following the ethical standards of the Committee on Experimental Rights of the 2008 Helsinki Declaration [46].

Statistical analysis. The arithmetic mean of the indicators $(\mathrm{M})$, standard deviation $(\sigma)$ and standard error (m) were determined. The significance of differences in the average values of independent samples evaluated by parametric methods applying Student's t-test. The differences between the values of indicators with a level of $p<0.05$ were considered significant.

\section{Results}

At the beginning of the experiment (September 2018), the morphofunctional values of the indicators of the female students of the EG and CG did not significantly differ, $\mathrm{p}>0.05$.

At the end of the experiment (June 2019), a significant difference was found in the values of the body mass index of female students in the EG, $p<0.05$ (Table 1).

By the end of the experiment, female students of EG had a decrease in body mass by $12.6 \%$ and an average BMI of $14.2 \%$. Body mass and BMI in female students of

Table 1. Morphological and functional indicators of female students in the EG and CG before and after the experiment $(\mathrm{M} \pm \mathrm{m})$

\begin{tabular}{|c|c|c|c|c|c|}
\hline \multirow{2}{*}{\multicolumn{2}{|c|}{ Parameters }} & \multicolumn{2}{|c|}{ Experimental group $(n=42)$} & \multirow{2}{*}{$\begin{array}{l}\text { Control group } \\
(n=44) \\
\text { Before }\end{array}$} & \multirow[b]{2}{*}{ After } \\
\hline & & Before & After & & \\
\hline \multirow{6}{*}{\multicolumn{2}{|c|}{$\begin{array}{l}\text { Body length, } \mathrm{cm} \\
\text { Body mass, } \mathrm{kg} \\
\text { BMI, } \mathrm{kg} / \mathrm{m}^{2} \\
\text { Chest circumference, } \mathrm{cm} \\
\text { Systolic blood pressure, } \mathrm{mm} \mathrm{Hg} \\
\text { Diastolic blood pressure, } \mathrm{mm} \mathrm{Hg}\end{array}$}} & $163.6 \pm 0.70$ & $164.7 \pm 0.73$ & $163.8 \pm 0.68$ & $164.4 \pm 0.72$ \\
\hline & & $73.5 \pm 0.93$ & $64.2 \pm 0.89 *$ & $72.8 \pm 0.89$ & $70.2 \pm 0.93$ \\
\hline & & $27.5 \pm 0.35$ & $23.6 \pm 0.29 *$ & $27.1 \pm 0.34$ & $26.3 \pm 0.33$ \\
\hline & & $84.6 \pm 0.58$ & $84.1 \pm 0.57$ & $85.1 \pm 0.55$ & $85.9 \pm 0.56$ \\
\hline & & $122.6 \pm 1.35$ & $117.0 \pm 1.42 *$ & $125.4 \pm 1.33$ & $123.5 \pm 1.44$ \\
\hline & & $69.8 \pm 1.26$ & $66.3 \pm 1.18 *$ & $65.3 \pm 1.23$ & $67.7 \pm 1.32$ \\
\hline \multirow{2}{*}{$\begin{array}{l}\text { Martine-Kushelevsky } \\
\text { test (HR, b/10 s) }\end{array}$} & Before load & $14.9 \pm 0.35$ & $14.5 \pm 0.32$ & $14.3 \pm 0.24$ & $14.2 \pm 0.34$ \\
\hline & After load & $22.2 \pm 0.31$ & $21.3 \pm 0.36 *$ & $21.6 \pm 0.16$ & $20.8 \pm 0.20 *$ \\
\hline \multicolumn{2}{|c|}{$\begin{array}{l}\text { Recovery time of heart rate after } 20 \\
\text { squats, s }\end{array}$} & $95.03 \pm 0.3$ & $78.8 \pm 0.45 *$ & $94.4 \pm 0.34$ & $93.8 \pm 0.46$ \\
\hline \multicolumn{2}{|c|}{ Robinson index, c.u. } & $109.6 \pm 1.23$ & $101.8 \pm 0.72 *$ & $107.6 \pm 0.87$ & $105.5 \pm 0.70$ \\
\hline \multirow{2}{*}{$\begin{array}{l}\text { Handgrip Strength } \\
\text { Test, kg }\end{array}$} & Left hand & $23.3 \pm 0.46$ & $26.8 \pm 0.53 *$ & $24.3 \pm 0.28$ & $26.4 \pm 0.29 *$ \\
\hline & Right hand & $24.5 \pm 0.32$ & $27.1 \pm 0.37^{*}$ & $25.0 \pm 0.29$ & $27.4 \pm 0.28 *$ \\
\hline \multirow{2}{*}{ Power Index, \% } & Left hand & $31.7 \pm 0.49$ & $41.8 \pm 0.53 *$ & $33.1 \pm 0.58$ & $37.6 \pm 0.68 *$ \\
\hline & Right hand & $33.3 \pm 0.41$ & $42.2 \pm 0.55 *$ & $34.3 \pm 0.53$ & $39.0 \pm 0.71 *$ \\
\hline
\end{tabular}

Note. ${ }^{*}$ The significant difference in values at the end of the experiment $(p<0.05)$ 
CG decreased by $3.6 \%$ and $4.1 \%$, respectively.

There was a decrease in the values of the MartineKushelevsky test parameter "before the load" among female students of EG by $2.7 \%$, in the $C G$ - by $0.7 \%$. After performing 20 squats, the female students of EG showed a decrease in heart rate by $4.05 \%$, the CG - by $3.7 \%$. The recovery time of heart rate "after exercise" in the $\mathrm{CG}$ decreased by $0.6 \%$, in the EG by $17 \%$. This indicates that the recovery of heart rate in the EG occurred 28.3 times faster than in the CG. The Robinson index in female students of EG decreased by 3.6 times relative to the CG (7.1\% and $1.95 \%$, respectively). After the experiment, the values of functional indicators of the cardiovascular system in female students of the EG were higher compared to the CG.

\section{Discussion}

The WHO materials [29] emphasize the importance of controlling and preventing overweight and obesity by normalizing the nutrition of people and the widespread use of physical activity of all population groups in different countries.

The physical aerobic activity allows the body to not only split fats [47], but also helps to improve the functional characteristics of the cardiorespiratory system. This is confirm with studies carried out by other authors [48]. This is especially important for overweight female students, because they have lower values of the cardiovascular system and external respiration parameters than students with normal mass.

At the end of the experiment, the female students of the EG increased the strength of the left hand by $15.0 \%$, the right hand - by $10.6 \%$. The increase of strength value indicator of the left and right hands in the female students of the CG was lower: $8.6 \%$ and $9.6 \%$ (left and right hand), respectively.

Compared to the beginning of the experiment, the power index increased in both groups. The power index in the EG increased 2.3 times for the left hand and in 1.9 times for the right hand. Other researchers [49] determined the similar dependence of the physiometric indicators of the human body on the body mass index.

The increase in the physical fitness of the female students in the EG and the CG was determined at the end of the experiment. The results of their motor tests confirm that (Table 2).

The significant improvement in motor qualities in female students of EG was defined in five out of seven tests (Table 2). Indicators of speed (30 m run test), muscle strength of the upper shoulder girdle [Bent Arm Hang Test (two hands), s; Cadence Push-Up Test, quantity of times], trunk muscle strength [Eurofit Sit Up Test (for $30 \mathrm{~s}$ ), quantity of times] and dynamic strength of lower limb muscle [Standing Long Jump Test (Broad Jump), $\mathrm{cm}]$. The significant increase is fixed in three out of seven motor tests In female students of the CG: trunk muscle strength indicators, flexibility and dynamic strength of the lower limb muscle improved.

Improving the indicators values of motor qualities of female students in EG is associated with their higher physical activity and increased muscle component in the body. It is also associated with BMI normalizing. Studies [50-52] showed that the physical fitness of youth with overweight is significantly lower than that of students with normal mass. These data and the results of our research confirm the relevance of body mass normalizing in female students to increase their physical fitness.

It was shown [3] that classes only according to the standard methodology of physical education do not always lead to a positive result. Therefore, researchers [53] think that additional classes on correction of body mass are necessary.

High efficiency of mastering the educational material of the discipline was shown: Testing of pedagogical technologies "inverted class" [37]; the use of digital technologies for physical training in higher military educational institutions [54]; the use of information and communication technologies in students' physical

Table 2. Results of motor tests of female students in the EG and CG before and after the experiment $(M \pm m)$

\begin{tabular}{|c|c|c|c|c|}
\hline \multirow[t]{2}{*}{ Parameters } & \multicolumn{2}{|c|}{ Experimental group $(n=42)$} & \multicolumn{2}{|c|}{$\begin{array}{l}\text { Control group } \\
(n=44)\end{array}$} \\
\hline & Before & After & Before & After \\
\hline $1000 \mathrm{~m}$ run, $\min , \mathrm{s}$ & $7.20 \pm 0.56$ & $7.04 \pm 0.55$ & $7.02 \pm 0.26$ & $7.24 \pm 0.27$ \\
\hline $30 \mathrm{~m}$ run of the high start, s & $6.23 \pm 0.06$ & $5.86 \pm 0.06 *$ & $6.22 \pm 0.08$ & $6.18 \pm 0.05$ \\
\hline Bent Arm Hang Test (two hands), s. & $2.89 \pm 0.30$ & $3.8 \pm 0.32 *$ & $2.32 \pm 0.37$ & $3.12 \pm 0.43$ \\
\hline $\begin{array}{l}\text { Cadence Push-Up Test, quantity of } \\
\text { times }\end{array}$ & $16.1 \pm 0.55$ & $19.5 \pm 0.63^{*}$ & $17.0 \pm 0.44$ & $18.2 \pm 0.55$ \\
\hline $\begin{array}{l}\text { Eurofit Sit Up Test (for } 30 \mathrm{~s} \text { ), } \\
\text { quantity of times }\end{array}$ & $15.7 \pm 0.37$ & $17.6 \pm 0.43 *$ & $15.9 \pm 0.3$ & $17.0 \pm 0.29 *$ \\
\hline Standing Forward Bend, cm & $14.1 \pm 0.56$ & $14.7 \pm 0.58$ & $14.5 \pm 0.23$ & $16.7 \pm 0.29 *$ \\
\hline $\begin{array}{l}\text { Standing Long Jump Test (Broad } \\
\text { Jump), cm }\end{array}$ & $150.2 \pm 2.4$ & $158.2 \pm 2.9 *$ & $151.3 \pm 1.9$ & $158.5 \pm 2.1 *$ \\
\hline
\end{tabular}

Note. * The significant difference in values at the end of the experiment $(p<0.05)$ 


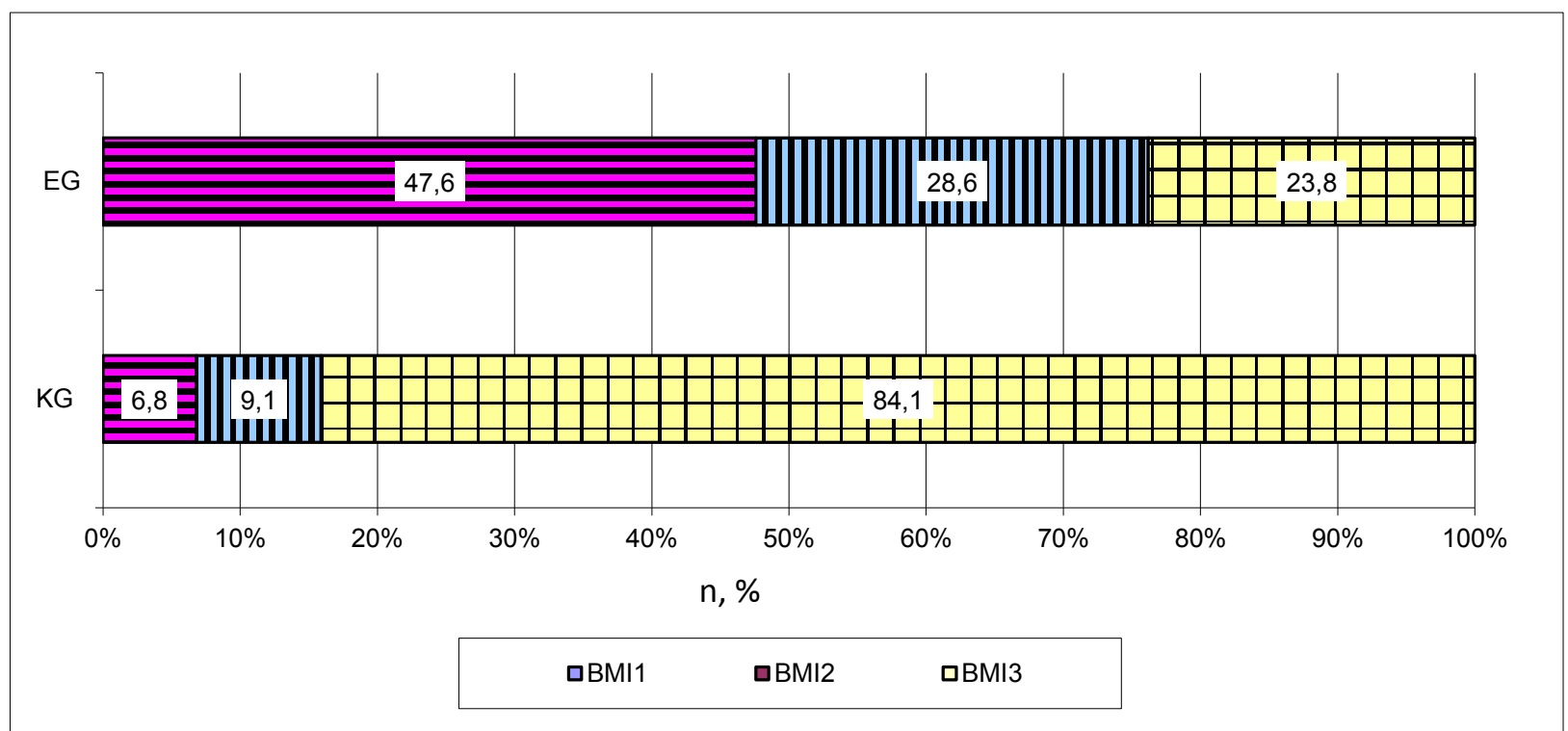

Fig. The results of the pedagogical experiment on the correction of body mass of students: EG - experimental group; CG - control group; BMI1 - body mass index (normal); BMI2 - body mass index (decreased); BMI3 - body mass index (unchanged); $\mathrm{n} \%$ - the number of students, \%.

education $[35,36]$.

The results of the pedagogical experiment on the correction of the body mass of students using the integrative method "inverted class" and digital learning given in the figure.

The BMI corresponded to normal values in 20 female students of EG (47.6\%) at the end of the experiment. The BMI decreased by $13.8 \%$ in 12 female students $(28.6 \%)$. The BMI did not change in 10 female students $(23.8 \%)$. The BMI decreased to normal values in 3 female students $(6.8 \%)$ in the control group. The BMI decreased by $5.4 \%$ in 4 female students $(9.1 \%)$. The body mass index did not change in 37 female students (84.1\%).

The use of visual familiarization of female students with educational material ("Elective courses in physical education and sports") allows improving the quality of teaching the subject; increase the motor density of the class; reduce the time for the explanation and demonstration of motor actions; to achieve the body mass normalization in a significant number of students.

\section{Conclusion}

The use of standard physical fitness technologies in physical education to normalize the mass characteristics of students is not always effective. This provokes the necessity to improve the pedagogical methods and of training and education means aimed at body mass correcting.

The integrative pedagogical technique proposed by the article authors based on cognitive teaching methods. The combination of the "inverted class" method and digital learning considered to be a more effective pedagogical technique than the traditional one.

Such organization and conducting the academic classes and independent work of female students allowed increasing the motor density of the class; correct body mass; improve the functional characteristics of the cardiovascular system and the physical fitness of female students; increase motivation and interest in physical activity.

\section{Conflict of interest}

The authors report no conflict of interest.

\section{References}

1. WHO. Obesity and overweight. Fact sheet. [Internet]. Reviewed February 2018. [updated 2019 Jun 15; cited 2019 Nov 5]. Available from: https://www.who.int/news-room/ fact-sheets/detail/obesity-and-overweight

2. Global Strategy on Diet, Physical Activity and Health. [Internet]. WHO, 2004. [updated 2019 Jun 15; cited 2019 Nov 5]. Available from: https://www.who.int/dietphysicalactivity/ strategy/eb11344/strategy_english_web.pdf

3. Bubnenkova OM. Somatic and physical condition of children with excess body mass. Uchenye zapiski universiteta im. P.F. Lesgafta. 2015;11(129): 64-67. (In Russian)

4. Moskovchenko ON, Zakharova LV, Tretyakova NV, Lyulina NV, Kattsin OA, Savolaynen GS.
Application of Hardware and Software Complex for Individualisation of Students' Sport and Recreational Physical Activities. Obraz Nauka 2019;21:124-49. https://doi.org/10.17853/1994-5639-2019-1-124-149

5. Chaudhuri S, Das B. Body proportions in human physique: A study related to somatometric measurements - some observations. Anthropology. 1990;28(1):19-26.

6. Lee SY, Gallagher D. Assessment methods in human body composition. Curr. Opin. Clin. Nutr. Metab. Care. 2008;11(5):566-572. https://doi.org/10.1097/MCO.0b013e32830b5f23

7. Obesity: preventing and managing the global epidemic. Report of a WHO consultation. World Health Organ Tech Rep Ser, 2000;894:i-xii, 1-253. 
8. Yusuf S, Hawken S, Ounpuu S. Effect of potentially modifiable risk factors associated with myocardial infarction in 52 countries (the INTERHEART study): Case-control study. Lancet, 2005;9438:937-952. https://doi.org/10.1097/00008483-200501000-00013

9. Goldaeva PR, Pavlenko OA. The incidence of obesity among students of Tomsk. Modern problems of science and education, 2016;6: 25-30.

10.Docenko VA, Kononenko IA, Mosijchuk LV. Monitoring the nutritional status of the residents of St. Petersburg. Voprosy pitaniia. 2015;3:58-63. (In Russian)

11. Choudhary A, Donnelly L, Racadio J, Strife J. Diseases Associated with Childhood Obesity. American journal Roentgenology. 2007;188:1118-1130. https://doi.org/10.2214/AJR.06.0651

12.Egorycheva EV, Musina SV. Study of deviations body mass in today's college students. Sovremennye issledovaniia social'nykh problem. 2011;8(4):57-61. (In Russian)

13.Solodovnikova IuV, Metina KI, Sakharova OB, Kiku PF, Babko SV. Nutrition and physical development of students (retrospective evaluation). Health. Medical ecology. Science, 2017;1(68):19-23. (In Russian) https://doi.org/10.5281/ZENODO.345608

14.Peshkov MV, Sharajkina EP. Body mass index in students: the present state of the problem. Sibirskoe medicinskoe obozrenie. 2014;4:49-56. (In Russian) https://doi.org/10.20333/25000136-2014-4-49-56

15.Enikeev BV. Prediction of pregnancy and childbirth in women with a body weight deficit. St. Petersburg; 2006. (In Russian)

16.Karushina LI, Nikitina EA, Muradian EM. The formation of reproductive function in girls with metabolic syndrome. Profilakticheskaia $i$ klinicheskaia medicina. 2010;3(3637):215-216. (In Russian)

17.Martinchik AN, Baturin AK, Peskova EV. Gender and age characteristics and the trends in prevalence of obesity in the adult population in Russia during the 1994-2012 period. Voprosy pitaniia. 2015;3:50-57. (In Russian)

18.Loseva TA, Golubkina NA, Rachkova VP. Physical and mental health of the first course students. Srednee professional'noe obrazovanie. Komplekt. 2011;8:46-47. (In Russian)

19.Sadovskaia OA, Sitnikova EM, Shibanova MIu. Prospects of improving university students' health condition based on nutrition optimization. Medicina v Kuzbasse. 2013;3:58-62. (In Russian)

20.Zul'karnaev TR, Salimgaraeva AI, Povargo EA, Zul'karnaeva AT, Agafonov AI. Description of anthropometric indices and nutritional status in students in Ufa city. Gigiena $i$ sanitariia. 2012;4:63-65. (In Russian)

21.Aminova OS, Uvarova IuE, Tiatenkova NN. Estimating dietary intake and nutritional status of students. In the World of Scientific Discoveries, 2017;9(1):66-77. (In Russian) https://doi.org/10.12731/wsd-2017-1-66-77

22.Kalka E, Pastuszak A, Buśko K. Secular trends in body height, body weight, BMI and fat percentage in Polish university students in a period of 50 years. PLoSONE, 2019;14:e220514. https://doi.org/10.1371/journal.pone.0220514

23.Karabulut US, Romero Z, Conatser P, Karabulut M. Assessing Overweight/Obesity, Dietary Habits, and Physical Activity in Hispanic College Students. Exerc Med, 2018;2:5. https://doi.org/10.26644/em.2018.005

24.Kumah DB, Akuffo KO, Abaka-Cann JE, Affram DE, Osae EA. Prevalence of Overweight and Obesity among Students in the Kumasi Metropolis. Journal of Nutrition and Metabolism 2015;2015:1-4. https://doi.org/10.1155/2015/613207

25.Dereń K, Nyankovskyy S, Nyankovska O, Łuszczki E, Wyszyńska J, Sobolewski M, et al. The prevalence of underweight, overweight and obesity in children and adolescents from Ukraine. Sci Rep, 2018;8:3625. https://doi.org/10.1038/s41598-018-21773-4

26. Physical activity Fact sheet. [Internet]. WHO. [updated 2018 Feb15; cited 2019 Nov 5]. Available from: https://www.who. int/news-room/fact-sheets/detail/physical-activity

27.Abdullina LB. The formation of a healthy lifestyle of students in a modern university: a practice-oriented aspect. Zdorov'esberegaiushchee obrazovanie, 2014;2:78-82. (In Russian)

28.Interdepartmental strategy for the formation of a healthy lifestyle, prevention and control of noncommunicable diseases for the period up to 2025. Moscow; 2016. (In Russian)

29. Global action plan for the prevention and control of noncommunicable diseases 2013-2020. [Internet]. WHO. [updated 2019 Feb15; cited 2019 Nov 5]. Available from: https://apps.who.int/iris/handle/10665/94384

30.Taiutina TV, Lysenko AV, Taiutina TV, Lysenko DS, Nedoruba EA. The role of health-improving technologies in maintaining optimal body mass in women of different age. Sovremennye problemy nauki i obrazovaniia, 2014;3:45-52. (In Russian)

31.Wimalawansa SJ. Controlling obesity and its complications by elimination of causes and adopting healthy habits. $A d v$. Med. Sci. 2014;3(1): 1-15.

32.Vasilec VV, Kostiuchenko VF, Vrublevskij EP. Comparative analysis of changes of componential structure of the body under the influence of training loading of health-improving character. Uchenye zapiski universiteta im. P.F. Lesgafta, 2015. №1 (119). C. 48-53. (In Russian)

33.Jagiello W, Jagiello M, Kalina RM, Barczynski BJ, Litwiniuk A, Klimczak J. Properties of body composition of female representatives of the Polish national fencing team - the sabre event. Biology of Sport. 2017;34(4):401-6. 6. https://doi.org/10.5114/biolsport.2017.70526

34.Jagiello W. Differentiation of the body composition in taekwondo-ITF competitors of the men's Polish national team and direct based athletes. Archives of Budo. 2015;11:329-38.

35.Vinogradov GP, Grigor'ev VI, Vinogradov IG. Information support of physical culture of students. Uchenye zapiski universiteta im. P.F. Lesgafta, 2018;4(146):46-50. (In Russian)

36.Abramenko MN. Physical education of students of special medical groups using an interactive tutorial for selfstudy. Uchenye zapiski universiteta im. P.F. Lesgafta, 2018;2(156):9-12. (In Russian)

37.Sorokin VP, Androsov AM, Sorokina IuV. The possibility of innovative «inverted class» technology use at physical training lessons in higher military educational institutions. Aktual'nye problemy fizicheskoj $i$ special'noj podgotovki silovykh struktur, 2016;4:57-60. (In Russian)

38.Neverova LV, Plotnikov ES. Use of Technology of Videocases in System of Post-Degree Education. Molodoj uchenyj. 2017;4:376-378. (In Russian)

39.International Standards for Anthropometric Assessment. 2001. [Internet] 2017 Nov 1 [updated 2018 Jan 1; cited 2019 Nov 8]. Available from: http://www.ceap.br/material/ MAT17032011184632.pdf

40.Global Database on Body Mass Index (BMI). [Internet]. WHO. [updated 2019 Feb15; cited 2019 Nov 5]. Available 
from: https://www.who.int/nutrition/databases/bmi/en/

41.Robinson BF. Relation of heart rate and systolic blood pressure to the onset of pain in angina pectoris. Circulation, 1967;35:1073-1083. https://doi.org/10.1161/01.CIR.35.6.1073

42.Nikitina OS, Yevsey AV, Narezkina LP, Pereverzev VA. Normal physiology. Practicum manual for specialty “Stomatology”. Minsk: BSMU; 2016.

43.Maternal anthropometry for prediction of pregnancy outcomes: memorandum from a USAID/WHO/PAHO/ MotherCare meeting. Bull World Health Organ, 1991;69:523-32.

44.Prokopenko LA. Physical fitness testing students based on the standards of the complex "Ready for labour and defence". Sovremennye naukoemkie tekhnologii, 2017;9:130-134. (In Russian)

45.The president's challenge: Physical fitness test. 2011. [July 14, 2011]. Available from: https://www.neoshosd.org/site/ handlers/filedownload.ashx?moduleinstanceid $=5912 \&$ datai $\mathrm{d}=1087 \&$ FileName $=$ Presidential\%20Fitness\%20booklet.pdf

46.World Medical Association Declaration of Helsinki: Ethical Principles for Medical Research Involving Human Subjects. JAMA, 2013;310:2191. https://doi.org/10.1001/jama.2013.281053

47.Iakubovskij DA, Zimnickaia RE. Substantiation of directions of 25-35 years women fitness training of various somatic with an average level of physical fitness. Vestnik Polockogo gosudarstvennogo universiteta. 2015;15:127-133. (In Russian)

48.Razina AO, Runenko SD, Achkasov EE. The role of physical rehabilitation in the complex management of obesity and overweight correction. Mediko-social'naia ekspertiza $i$ reabilitaciia. 2016;19(1):46-53. (In Russian) https://doi. org/10.18821/1560-9537-2016-19-1-46-53.

49.Schembre SM, Geller KS. Psychometric Properties and Construct Validity of the Weight-Related Eating Questionnaire in a Diverse Population. Obesity, 2011;19:2336-44. https://doi.org/10.1038/oby.2011.96

50.Paolillo FR, Milan JC, Bueno P de G, Paolillo AR, Borghi-Silva A, Parizotto NA, et al. Effects of excess body mass on strength and fatigability of quadriceps in postmenopausal women: Menopause. The Journal of The North American Menopause Society, 2012;19:556-61. https://doi.org/10.1097/gme.0b013e3182364e80

51.Onyiriuka AN, Egbagbe EE. Anthropometry and Menarcheal Status of Adolescent Nigerian Urban Senior Secondary School Girls. Int J Endocrinol Metab, 2013;11. https://doi.org/10.5812/ijem.8052

52.Vivian Heyward, Ann Gibson. Advanced Fitness Assessment and Exercise Prescription. 2014.

53.Kim TK, Sokolova VS, Dias Luk'ianova MI. The program normalization of body weight in girls of 14-15 years oldoverweight using modern methods of control of active and passive components of body composition. Sovremennye problemy nauki i obrazovaniia, 2017;5:34-40. (In Russian)

54.Sorokin VP, Androsov AM, Ivashchenko DE, Timofeev IIu, Kolbaia IM. Digital technologies in practice of physical training in higher military educational institution. Uchenye zapiski universiteta imeni P.F. Lesgafta, 2018;7(161):257262. (In Russian)

\section{Information about the authors:}

Kolokoltsev M.M.; (Corresponding author); Doctor of Medical Sciences, prof.; http://orcid.org/0000-0001-6620-6296; mihm49@mail.ru; Irkutsk National Research Technical University; Irkutsk, Russia.

Ambartsumyan R.A.; http://orcid.org/0000-0001-6620-6296; mihm49@mail.ru; Irkutsk National Research Technical University; Irkutsk, Russia.

Tretyakova N.V.; Doctor of Pedagogical Sciences, prof.; http://orcid.org/0000-0002-8820-3114; tretjakovnat@mail.ru; Russian State Professional Pedagogical University ; Ekaterinburg, Russia.

Jagiello W.' Doctor of Sciences, prof.; http://orcid.org/0000-0001-7417-4749; wjagiello1@wp.pl; Gdansk University of Physical Education and Sport; Gdansk, Poland.

Yermakova T.S.; Doctor of Pedagogical Sciences; assistant prof;; http://orcid.org/0000-0002-3081-0229; yermakova2015@ gmail.com; Kharkiv State Academy of Design and Arts ; Kharkiv, Ukraine.

\section{Cite this article as:}

Kolokoltsev MM, Ambartsumyan RA, Tretyakova NV, Jagiello W, Yermakova TS. Integrative pedagogical technique of physical education of female students with overweight. Physical education of students, 2019;23(6):306-312.

https://doi.org/10.15561/20755279.2019.0605

This is an Open Access article distributed under the terms of the Creative Commons Attribution License, which permits unrestricted use, distribution, and reproduction in any medium, provided the original work is properly cited http://creativecommons.org/licenses/by/4.0/deed.en

Received: 03.11.2019

Accepted: 17.12.2019; Published: 18.12.2019 